\title{
Effectiveness of Marzano's Dimensions of Learning Model in the Development of Creative Thinking Skills among Saudi Foundation Year Students
}

\author{
Azizah Saad Al Rowais ${ }^{1, *}$ \\ ${ }^{1}$ Curriculum and Instruction, College of Education, Al Imam Mohammad Ibn Saud Islamic University, Riyadh, \\ Saudi Arabia \\ *Correspondence: Curriculum and Instruction, College of Education, Al Imam Mohammad Ibn Saud Islamic \\ University, Riyadh, Saudi Arabia. E-mail: azizahsd08@gmail.com
}

Received: June 17, 2019

Accepted: August 2, 2019 Online Published: August 15, 2019

doi:10.5430/wje.v9n4p49

URL: https://doi.org/10.5430/wje.v9n4p49

\begin{abstract}
The present study attempts to identify the effectiveness of Marzano's dimensions of learning model in developing creative thinking skills among the students of the foundation year at Prince Sattam bin Abdulaziz University, Saudi Arabia. To achieve the study objective, a scale of creative thinking skills and a guide were prepared by the author to clarify how to teach according to the dimensions of learning. The study utilized a quasi-experimental method to apply the learning model to (25) female students representing the control group who were traditionally taught the selected unit and an experimental group of (25) students who studied the same unit using Marzano's dimensions of learning model, and pre and posttest for creative thinking skills applied to both groups. The study results showed statistically significant differences between score means of the two groups suggesting the experimental group excellence in creative thinking. The study recommended redesigning the university courses to comply with Marzano's dimensions of learning model.
\end{abstract}

Keywords: Marzano's dimensions of learning model, creative thinking, creative thinking skills, foundation year

\section{Introduction}

Creative thinking has helped develop the learning process and make it positive. Thus, it has to be promoted and taught to students throughout all educational stages. Creative thinking, as an educational goal, does not target a specific educational level, so all age groups should adopt it. All society institutions, especially the educational ones, assume the responsibility for developing creativity and its skills. Developing students' thinking is based on different curricula or independent teaching programs that contribute to the development of their thinking skills if they offer the potential for teaching or training. That is, the creative skills require development and training because the traditional methods inhibit these skills and make the students lack creativity and intellectual production which involves novelty and diversity.

The author claims that educational institutions should develop their methods, teach their students thinking, and motivate them to free their intellectual and creative capacity to afford the burdens of the inconstant world. Consequently, it is necessary to find the optimal methods, which develop creative thinking and give the students of the Foundation Year the fundamental role in the educational process.

While teaching at the Saudi Universities, the author has noticed that the level of creative thinking skills of the students is low. This finding matches previous pieces of literature on creative thinking and skills, such as Al-Aklabi (2008), Al-Ahmadi (2008), Fathalla (2009), Al-qadi (2009), Abu-Azra (2010), Al Faleh (2010), Prodfit (2010), Abu Lahia (2011), Yee et al. (2011), Shamri (2012), Sriwongchai, Jantharajit and Chookhampaeng (2015), Widiana and Jampel (2016), and Sandro (2017).

Additionally, the author conducted a pilot study that involved attending some lectures in the Foundation Year. She surveyed (11) professors and (24) students on the practice of creative thinking skills and higher-order thinking. The study showed the adoption of lower-order thinking rather than higher-order thinking in teaching. Nine professors 
$(81.82 \%)$ and twenty students $(83.33 \%)$ attributed that to the teaching method in which the professor plays the major role and utilizes teaching strategies which do not stimulate creativity. Accordingly, it has been necessary to find the optimal methods to develop creative thinking skills among the students of the Foundation Year.

Recently, teaching models and strategies have emerged based on the application of basics and fundamentals derived from the results of the comprehensive researches in the field of cognitive learning, such as Marzano's dimension of learning. This model resulted from the educational effort of Marzano and a comprehensive team of educators who investigated and evaluated the educational researches, especially in cognitive psychology, measurement, and evaluation on the processes of learning and thinking over the past 30 years. They also drew on the perspectives and researches of more than (90) experts from (18) districts in the United States of America and Mexico (Marzano et al., 1998, 1999).

This model is based on the constructive philosophy which makes both the teacher and learner active. It also involves that knowledge is the context which builds the individual through experiences and interactions with the elements and variables of the surrounding environment. This knowledge helps the individual interpret experiences and life situations. Moreover, it shows teaching as an investigative process that aims to make the learner understand what is happening around him/ her. It asserts the mental habits as well (Marzano et al., 2000a).

Marzano postulates that the learning process involves an interaction between five types of thinking, i.e. dimensions of learning, which reflect how the mind works within learning in order to change the planning procedures, curriculum design, and evaluation. (Marzano et al., 2000b; Alsalamat, 2007). Dimension 1 "positive attitudes and perceptions about learning" comprises two aspects; classroom climate and classroom tasks. It attracts the students and stimulates them to learn. Dimension 2 "acquisition and integration of knowledge" includes two types, namely declarative knowledge and procedural knowledge. Students do activities which help them acquire new knowledge and relate it to prior knowledge. In dimension 3 "extension and refinement of knowledge", students answer the openended questions and do the activities which extend and refine knowledge. In dimension 4 "meaningful use of knowledge", the student has the opportunity to use what he/ she has acquired meaningfully. Dimension 5 "productive habits of mind" involves the creation of situations and problems that enable the student to employ thinking skills to help acquire new information to be utilized it in life situations and problems.

The educators use this model to design and plan the educational units, including the experiences they have to create an active and fruitful learning environment in which both the teacher and student can achieve the desired goals of the educational process. It is a classroom instruction model which involves how to plan and implement lessons, curricula design, or an evaluation of the students' performance. Its premise is that the five dimensions of learning are essential to successful learning. It is also deployed to develop teaching methods in the classrooms using carefully designed performance tasks to enable the students to verify their perception about the concepts, application of knowledge, and utilization of the skills in their daily lives outside the classroom (Marzano et al., 2000a)

Some educators, e.g. Al-Momani, Al-Khatabia and Al-Qodah (2015), Hussein (2015), Al-Wassimi (2013), Mohamed (2011), Abd Alhaleem (2011), Al-Hossan (2007), Salih and Bashir (2005), and Al-Adgham (2005), define the advantages of Marzano's model of learning dimensions, which contribute to the development of creative thinking, as follows:

- It stimulates the students' minds and motivates them to learn through creating comfortable, delightful, and safe classroom environment and providing them with the facilitating aids and materials.

- It broadens knowledge through various activities, such as comparing, classifying, inductive reasoning, deductive reasoning, analyzing errors, and creating and analyzing support. These activities enable the students to think about the concepts they learn and to understand the relationship among the different parts of knowledge which is the essence of the thinking process.

- It makes the information provided to the students beneficial through employing it in life situations.

- It provides the strategy of student-centered learning where he/she discovers and implements the educational activities rather than being a negative recipient.

- It gives the student freedom of expression which motivates him/her to exert more efforts, think, and achieve.

- It creates an appropriate classroom environment and positive attitudes and perceptions of the learning environment and teaching methods which motivate the students to think properly. 
It provides the mechanism of discovery and experimentation supervised by the teacher who guides and motivates the learner. It is a comprehensive model that develops different thinking skills, such as creative thinking skills.

Several studies have addressed the effectiveness of the dimensions of learning model in developing creative thinking. For example, Alba'ali (2003) showed the excellence of the students who utilized this model in the learning processes test. Al-Iraqi (2004) revealed the effectiveness of the model-based learning activities in the development of thinking skills and Hassanien (2006) indicated the effectiveness of the model in the development of complex thinking. Additionally, Asfour (2007) reported the model's effectiveness in developing some dimensions of thinking, Al-Hossan (2007) demonstrated its effectiveness in the development of some thinking skills, and Alsalamat (2007) illustrated its effectiveness in the development of critical thinking skills. While Habib (2008) asserted this model's effectiveness in the development of decision-making skills, Othman (2009) confirmed its effectiveness in the development of metacognition skills, and Fathalla $(2009,2011)$ indicated its effectiveness in the development of the habits of mind. Kamel and Sayed (2010) revealed its effectiveness in the development of critical thinking skills and Suliman (2010) demonstrated its effectiveness in developing problem-solving skills. Furthermore, Mohamed (2011) showed its effectiveness in the development of thinking skills, Al-Arian (2011) reported its effectiveness in the development of scientific thinking skills, Al-Meselhi and Abdullah (2012) revealed its effectiveness in the development of mathematical thinking, and Abd Alkader (2012) demonstrated its effectiveness in developing higher-order thinking skills. While Hanafi (2013) indicated the effectiveness of the model-based program in the development of creative thinking skills among the first secondary grade students, Al-Wassimi (2013) revealed its effectiveness in developing creative thinking skills, and Mohamed (2014) and Al-Qabas (2014) reported its effectiveness in the development of mathematical thinking. Saad (2014) asserted the importance of the model in the development of probe thinking, Kazem and Mohamed (2014) demonstrated its effectiveness in the development of probe thinking, and Hussein (2015) reported its significant impact on critical thinking development. Furthermore, Radwan (2016) revealed the effectiveness of a program based on Marzano's dimensions of learning in the development of productive thinking skills.

Accordingly, the utilization of dimensions of learning model in teaching is generally important because it develops and expands knowledge and creates integration between its two types; the declarative and the procedural. It also creates positive attitudes and perceptions of learning. It facilitates the optimal use of the habits of mind for the learner. Furthermore, it integrates all aspects of the educational process commensurate with the abilities, capabilities, and intelligence level of the learners.

In conformity with the mission and objectives of Prince Sattam bin Abdulaziz University to achieve continuing education, teach learners self-learning skills, and develop higher-order thinking skills as well as the needs of the Saudi community to match and integrate the different educational advancements - according to the educational theories- in curricula, the author has been motivated to conduct the present study. It reformulates and reorganizes the unit of interpersonal communication in the course of communication skills in the light of the Marzano's dimensions of learning model. It also defines its effectiveness in developing creative thinking skills among the students of the Foundation Year at Prince Sattam bin Abdulaziz University. Thus, the present study attempts to identify the effectiveness of Marzano's dimensions of learning model in developing creative thinking skills among the students of the Foundation Year.

\section{Theoretical Background}

\subsection{Marzano's Dimensions of Learning Model}

The dimensions of learning model are based on the structural philosophy which asserts that knowledge is a prerequisite for building the individual's experiences and interactions with the surrounding elements and variables. The learner continues gaining the experiences that enable him/ her to link the new and prior information (Baali, 2003).

This model is based on a cohesive intellectual unit combining flexibility in adapting the theory to everyday classroom practices and the rigidity of the units' functional connection. It is associated with the theoretical grounding to achieve obvious and profound objectives and to build the students' productive habits of mind. It integrates three theories essential to educational interaction, i.e. Vygotsky's sociocultural theory, brain-based learning theory, and problem-centered learning theory (Marzano et al., 1999). It is also based on the dimensions of thinking as a practical model in which the fundamentals, derived from the previous theories, formulate an educational framework that helps improve the quality of education. 
Accordingly, the author argues that the dimensions of learning model is significant in the field of education because it adopts the latest theories of cognitive psychology and neuropsychology.

\subsubsection{Concept of the Model}

The dimensions of learning model is an educational model that aims to train the learner on how to think while learning based on the development of achievement and thinking skills through the interaction between five types of learning: Positive attitudes and perceptions of learning, acquisition and integration of knowledge, extension and refinement of knowledge, meaningful use of knowledge, and productive habits of mind (Sorour, 2013).

It is an instructional model suggesting that everything the teacher performs develops a particular type of the students' thinking. According to Kamel (2011), the learning outcomes are organized in the aforementioned five dimensions and students have to experience them in order.

The author defines the model as an instructional classroom framework that involves five procedural steps focusing on the interaction between five dimensions of learning and the Foundation Year students' experience: Positive attitudes and perceptions about learning, acquisition and integration of knowledge, extension and refinement of knowledge, meaningful use of knowledge, and productive habits of mind.

\subsubsection{Dimensions of the Model}

Marzano proposes that the learner experiences five dimensions of thinking while learning. He calls them the five dimensions of learning which represent the outcomes or the dimensions of thinking, indicating how the mind works, as follows:

Dimension 1: Positive attitudes and perceptions about learning

Attitudes and perceptions affect students' abilities to learn. Some of them have a positive effect, while others have a negative one. A primary focus of effective instruction, then, is helping students to establish positive attitudes and perceptions about the classroom and about learning. Otherwise, students have a little chance of learning proficiently, if at all (Marzano et al., 2000).

According to Asfour (2007) and Marzano and Kendall (2007), Marazona argues that the development of the positive attitudes and perceptions about learning involves two aspects that the teacher should take into account: attitudes and perceptions about learning environment. They help the students feel accepted, safe, and comfortable. They also develop order perception, and attitudes and perceptions about the classroom tasks, helping the students perceive that the value of tasks and their ability to do them.

Dimension 2: Acquisition and integration of knowledge

The dimensions of learning model focus on the need to teach the content and the concept that thinking processes are an integral part of the content knowledge. They both form the basis of learning to create an educated and experienced learner. When the content is new, a teacher's instructional planning must focus on strategies that help students relate the new and prior knowledge, organize the new knowledge in meaningful ways, and make it part of their long-term memory (Abd-Almoneim, 2001; Waters and Marzano, 2006).

The purpose of class education, in general, and instruction, in particular, is the student's acquisition of the necessary knowledge and helping him/her integrate this knowledge in the context of his/her experiences. The theorists of cognitive learning distinguish among the types of knowledge and give them specific definitions to perceive ways of thinking, how the mind works in learning, as well as methods of knowledge acquisition and storage. When planning lessons, the teacher adopts two types of knowledge. They are the declarative knowledge that states that the learner thinks in a concept or an issue recalling the relevant characteristics without doing a process or a procedure and the procedural knowledge which requires doing practical procedures according to various steps (Marzano et al., 2000; Soliman, 2004; Alsalamat, 2007; Afnan, 2011).

Dimension 3: Extension and refinement of knowledge

Acquiring and integrating knowledge is not the end of the learning process. Learners extend and refine their knowledge, adding new distinctions and making further connections. Although traditional learning is based on acquitting and retaining information, good learning involves extending and refining knowledge. Furthermore, the dimensions of learning model offer various mental activities or processes which stimulate thinking to extend and refine information, as follows: comparing, classifying, inductive reasoning, deductive reasoning, analyzing errors, creating and analyzing support, analyzing perspectives, and abstracting (Al-Gafri, 2011).

Dimension 4: Meaningful use of knowledge 
The pursuit of knowledge is a worthy goal, but it is not enough. We seek knowledge in order to use and benefit from it and give it a meaning. Acquiring and deepening knowledge without utilization is valueless. The effectiveness of this dimension is based on the teacher's keenness on accurate planning, organization, and creation of actual desire and motivation to help students benefit from the information enormously (Marzano et al., 1999). Marzano defines five types of tasks that encourage the meaningful use of knowledge: Decision making, investigation, experimental inquiry, problem solving, and invention (Mohamed, 2003).

Dimension 5: Productive habits of mind

Mental habits are important variables related to the students' academic performance throughout the different stages of education. Qattami (2007a) emphasized the importance of teaching, reinforcing, creating, evaluating and discussing them with students as well as providing them with the necessary reinforcement to adhere to them as an integral part of their mental structure.

Marzano defines several mental habits that learners should acquire in the educational process, as follows: self-regulated learning which involves the student's awareness of thinking, planning, essential resources, response to the others' feelings, and critical thinking which appears in accuracy, clarity, open-mindedness, restraining impulsivity, and sensitivity to the others feelings. It also involves creative thinking which appears in engaging intensely in tasks even when the answers or solutions are not immediately apparent, pushing the limits of knowledge and abilities, as well as creating standards of evaluation and new methods to handle the situation unconventionally (Soliman, 2004; Alsalamat, 2007; Al-Makhzoumi \& Al-Bataniah, 2012).

The author reports that for creative thinking, students are trained to develop mental habits through encouraging them to plan, use resources, evaluate their performance, be accurate and clear, create and engage in tasks even when answers or solutions are not immediately apparent.

Accordingly, the author contends that the five dimensions of learning do not operate in isolation but work together. Marzano asserts that learning occurs according to the student's attitudes and perceptions (dimension 1) and utilization of the productive habits of mind (dimension 5). Dimensions 1 and 5 are always factors in the learning process. Given that proper attitudes and perceptions are in place and productive habits of mind are being used, the learner acquires and integrates new knowledge (dimension 2), expands and refines knowledge (dimension 3), and uses knowledge meaningfully in his/her everyday life (dimension 4). Thus, the most effective learning is a product of the interaction of these five dimensions involved in Marzano's dimensions of learning model (Marzano, 2000).

\subsubsection{Utilizing the Dimensions of Learning Model in Teaching}

Mikhael (2009), Marzano defines the steps of teaching with his model, as follows:

- Analyze, observe and discuss the student's thinking through asking guiding, reinforcing, and creative questions.

- Organize the classroom and learning environment in a way that permits learner's participation in the different processes of thinking within the lessons of cooperative learning.

- Divide the students into small groups, assign them the responsibilities and tasks, and define the different roles of each participant.

- Prepare worksheets and activities involving detailed analytical questions of the tasks the individual should carry out and which aims to identify his/her educational experiences and thinking abilities.

- Provide support, feedback, guidance and assistance in an organized manner that achieves the goals independently; with no direct intervention from the teacher.

- Plan the educational task scientifically and logically so as not to cause any defect in the tasks and skills, especially if the learner carries out the task for the first time, and define how the teacher provides assistance when required.

The author states that these steps illustrate the importance and benefits of the model in regulating and arranging knowledge as well as the skills which help integrate, refine, and use knowledge meaningfully.

\subsection{Creative Thinking Skills}

\subsubsection{Concept of Creative Thinking Skills}

Brahimi (2017) claimed that creative thinking is a mental activity, which results in finding new solutions to any problem encountering the individual. It is also a response to a situation or a problem solved in an appropriate 
manner. It involves three dimensions or skills (i.e. fluency, flexibility, originality, and elaboration).

Francie, Tim, and Tiffany (2013) define creative thinking skills as a developmental behavior similar to the growth of the tree. It begins with analyzing the skill to primary steps and abilities, based on the learner's initial behavior. Then, it is described and presented. Eventually, it is put into practice to be a normal behavior that is conducted when required.

Guo-Qing (2014) contends that thinking skills, especially creative thinking skills, increase the student's selfconfidence and abilities, cultivate the interest in classroom experiences, and enable him/her to play an effective and positive role reflected in his/her achievement performance.

Procedurally, creative thinking skills are a set of mental abilities that the student of the Foundation Year practices to generate enormous and new ideas and solution which involve flexibility, fluency and originality. They provide unconventional solutions to the problems relevant to the unit of interpersonal communication in the course of communication skills. They are estimated according to the total scores that the student obtains after calculating her responses to the items of the scale of creative thinking skills.

\subsubsection{Creative Thinking Skills}

Creative thinking comprises several skills utilized in the present study, as follows:

a. Fluency: The ability to generate the largest possible number of appropriate ideas. The creative individual has the potential to create several ideas easily and flexibly within a definite time compared to others (Al-Ghamdy, 2013). It has different types, such as verbal fluency, shapes fluency, ideas or meanings fluency, expressional fluency, and temporal fluency (Al-Mohamadawi, 2011).

b. Flexibility: The ability to think differently and openly and to perceive the problems from multiple aspects, so tremendous responses related to various situations are created (Al-Atoum, Al-Jarrah, and Beshara, 2011). It comprises two types:

- Spontaneous flexibility which indicates the individual's ability to generate several and various ideas relevant to a problem or a stimulant. He/she also tends to take the spontaneous initiative and the response does not satisfy $\operatorname{him} /$ her

- Adaptive flexibility which indicates the individual's ability to change his/her perspective towards the problem solution to generate various solutions. In other words, he/she adapts to the problem and its manifestations (AlSefi \& Abo Dyak, 2017).

c. Originality: Generating new ideas or methods, i.e. thinking differently and generating indirect and innovative ideas. It is estimated by calculating the number of extraordinary and unconventional ideas (Jarwan, 2010).

Accordingly, the author concludes that originality is different from fluency and flexibility, as follows:

- Originality does not refer to the number of creative ideas the individual generates, but it is based on the value and type of ideas. Thus, it is different from fluency.

- Originality does not refer to the teacher's antipathy to the frequency of conceptions or ideas like what occurs in fluency, but it refers to antipathy to the frequency of the others' actions. Thus, it is different from flexibility.

2.2.3 Strategies and Programs of Creative Thinking Development

Al-Bakr (2008), Abo-Galala (2006), Habib (2007), and Al-Taib, Adam, and Abdul Rahim (2007) claim that there are three substantial approaches to develop the students' creative thinking skills. They are:

a. Teaching thinking directly or independently from the course: It requires teaching thinking directly through designing programs and activities of thinking skills independent from courses. They are taught within a specific time and the content of the lesson should be simple.

b. Teaching thinking through integration in the course: It requires developing thinking skills indirectly through providing the educational environment which triggers thinking and develops its skills using teaching strategies in the classroom. It is based on the integration between thinking skills, which are a part of the class, and the course content. It also continues throughout the educational stages.

c. It integrates the approaches 1 and 2; thinking is taught as an independent course that has its teachers, classes, and tests. In addition, thinking skills are integrated into the content of the different courses.

The author utilizes the dimensions of learning model in the unit of interpersonal communication in the course of communication skills. She also evaluates its impact on developing creative thinking skills among the students of the 
Foundation Year. To be more precise, she deploys approach 2 because she states that it is so beneficial, effective, and constant that it makes thinking skills a part of the course.

\subsubsection{The Role of Curricula and Teacher in the Development of Creative Thinking}

According to Abu Shakur (2013), the most important features of the curriculum that develops creative thinking are:

a. Developing the skills of creative and scientific thinking to promote the higher-order thinking and have the ability to distinguish what is good from what is bad.

b. Cultivating the interest in the processes of science, such as observing and interpreting the scientific, technological, sensory and perceptive phenomena, as well as avoiding the unrealistic interpretations of issues and problems.

c. Developing self-learning among learners so that they can rely on themselves to acquire knowledge.

d. Practicing the practicum course proficiently to help develop the professional aspect.

e. Asserting and developing the learners' originality as well as the interest in modernity, adhering to the values of the community.

f. Focusing on the practical aspects of the different theories - scientific and educational - to help learners adapt to the different life situations.

Al-Gharaybeh (2014), Ibrahim (2006), and Al-Najdi, Rashed, and Abd Alhadi (2005) report that the teacher plays an important role in the development of creative thinking skills because he/ she adopts the following methods:

- Ask questions that stimulate thinking and defining adequate time to think.

- Attentive listening and respect for diversity and openness.

- Encourage discussion and expression as well as accepting and appreciating ideas and opinions.

- Develop students' self-confidence through providing positive feedback.

- Provide the students with appropriate opportunities to handle express and solve problems.

- Provide students with information and skills that develop their creativity and skills.

- Assign tasks that enable students to connect the aspects of new and prior knowledge.

- Provide a learning environment that asserts students' familiarity with the meaning of each aspect of knowledge.

- Diversify teaching methods and activities when presenting the educational material.

The author argues that the teacher should identify students' creativity, create an appropriate environment, activate thought-provoking activities, communicate with students, encourage their answers, ask open questions that require multiple answers, and increase their confidence so that they can develop their creative thinking skills.

\subsubsection{The Educational Value of Creative Thinking Skills}

Creative thinking is a type of thinking that helps the individual create many mental outputs, e.g. generating ideas, discovering new relationships, and finding unfamiliar ways to solve different problems (Barker and Rudd, 2007).

Karwowski, Gralewski, Lebuda and Wisniewska (2010), Qattami (2007b), and Beghetto (2007) illustrate that the importance of creative thinking is represented in the following aspects:

- Improving teaching and learning process; effective learning is based on creativity, so learners' motivation, desire, and activity towards learning increase.

- Changing learners' thinking methods and increasing their ability to solve problems and discover new solutions.

- Raising the learners' awareness of the surrounding issues, helping them address the issues in different methods, and increasing their effectiveness in the situations they encounter.

- Increasing the efficiency of the students' mental activity and ability when addressing the situations.

Accordingly, the concern should be given to the student's creative thinking and development. Education has to provide all potentials to increase the effectiveness of his/her thinking. Only parents or teachers with advanced 
thinking skills or appropriate mental activity can promote it. To develop the student's creative thinking skills, the teacher should have the skill to detect the child's real abilities, activate the prior experiences to stimulate and employ the processes and skills of creative thinking. Finally, creative thinking is a mental process and a skill that requires special materials to be implied in the courses by a qualified teacher.

\section{Statement of the Problem}

The modern educational approaches assert the positive role of the student as the core of the educational process. However, reality contradicts this perspective. Educators report that the educational programs and methods of classroom education involve shortcoming represented by the students' low thinking abilities and filling their minds with redundant information through instruction and lecture in which the student is a recipient only. These methods are useless because they do not prepare him/her for life effectively. They are also inconsistent with today's requirement because they do not motivate students to think and develop creativity. They encourage memorization and imitation. They lack the diverse teaching methods that enable the students to adopt several skills in thinking, questioning and problem solving which help them lead productive and fulfilled lives.

In addition, the teacher lectures rather than giving concern to the questions and activities that stimulate students' thinking and raise questions relevant to the lesson. The students frequently ask questions that require low thinking skills. He/ she rarely asks questions with how? why? or what if? Therefore, it is necessary to provide the students with opportunities which enable them to gain experience trough creative thinking, employ modern methods to develop creative thinking, create an appropriate classroom environment to motivate them to practice their creative abilities, and avoid the approaches which hinder creative thinking, such as instruction and excessive homework which assert information acquisition.

To address this problem and to meet the needs of the Saudi community which require integrating learning advancements into curricula to employ educational theories in the development of curricula and thinking skills, the present study attempts to answer the following questions:" What is the effectiveness of Marzano's dimensions of learning model in the development of creative thinking skills (fluency, flexibility and originality) among Saudi Foundation Year students?

\section{Significance}

This study is important because it is an objective response to what the educators currently call for, i.e. the necessity for providing advanced teaching programs and strategies to develop the students' creative thinking. It also matches the modern educational approaches which motivate all officials to detect and put into practice the students' creative thinking skills. Moreover, its results help implement the mission of higher education, the objectives of the strategic plan and the Saudi Vision 2030 to obtain continuing education, teach students creative thinking skills, and motivate them to create.

It is also important for university students because the university teaches the students how to face the challenges and requirements of life, contributes to the community service and progress, and represents the rapid development of thinking, creativity and skills. In addition, it helps plan and develop curricula and teaching methods of university courses through implementing this model taking into account the need to review and modify the university courses to involve an interaction between the teacher and the student in the educational situations.

The dimensions of learning model are one of these methods. This study also provides a guide containing the behavioral objectives of the educational unit and clarifying how to implement Marzano's dimensions of learning model in teaching and evaluating the course. Furthermore, a scale of creative thinking skills for the students of the Foundation Year was prepared.

students representing the control group who were traditionally taught the selected unit and an experimental group of (25) students who studied the same unit using Marzano's dimensions of learning model, and pre and posttest for creative thinking skills applied to both groups.

\section{Hypothesis}

The study seeks to verify the following hypothesis: 
There are statistically significant differences between score means of the control group students (who were traditionally taught) and the experimental group students (who studied using Marzano's dimensions of learning model) in the post-test for creative thinking skills in favor of the experimental group.

\section{Limitations}

The study has been limited to:

Human and spatial limitations: A sample of the students of the Foundation Year at Prince Sattam bin Abdulaziz University who are enrolled in the course of communication skills.

- Temporal limitations: The unit of interpersonal communication in the course of communication skills for the students of the Foundation Year in the first semester of the academic year 2016/ 2017.

- Subject limitations: Three creative thinking skills (i.e. fluency, flexibility, and originality).

\section{Methodology}

\subsection{Method}

The study utilized a quasi-experimental method to identify the effectiveness of Marzano's dimensions of learning model in developing creative thinking skills among the students of the Foundation Year at Prince Sattam bin Abdulaziz University. Two equivalent groups were selected: A control group that utilized the traditional method and an experimental group which studied using Marzano's dimensions of learning model. Moreover, pre and posttests of creative thinking skills were applied to both groups.

\subsection{Population}

Students of the Foundation Year at Prince Sattam bin Abdulaziz University in the academic year 2016/2017.

\subsection{Sampling}

Two sections in the second level of the Foundation Year at Prince Sattam bin Abdulaziz University were randomly selected. One represented the experimental group of (25) students and the other represented the control group of (25) students.

\subsection{Tools}

To achieve the study objective, the author prepared educational materials, such as the teacher's manual to clarify how to teach and evaluate according to Marzano's dimensions of learning model and a scale of creative thinking skills (fluency, flexibility, and originality).

A. The teacher's manual and student's worksheet utilized in teaching according to Marzano's dimensions of learning model:

They were prepared as follows:

- The author selected, redesigned and retailored the unit of interpersonal communication in the course of communication skills taught to the $2^{\text {nd }}$ level students at the Foundation Year according to Marzano's dimensions of learning model.

- The author analyzed the content of the unit to define its objectives and the behavioral objectives of each lesson.

- The author prepared advanced charts of the knowledge item involved in each lesson and questions that stimulate students' thinking. At the beginning of the lesson, images, drawings and concept maps related to learning tasks are displayed, general and sub-ideas are identified, and a number of questions that require undertaking exploratory activities in the form of collaborative groups are asked. The educational tasks are also developed to acquire and deepen knowledge through clarifying the results in light of the facts provided by answering questions that help them achieve the objective. Students are guided to implement the educational tasks which require doing several mental activities, such as comparing, classifying, inductive reasoning, deductive reasoning, analyzing, constructing, and evaluating. In addition, they practice the experimental study skills (i.e. observation, interpretation, and deduction) where they acquire all information and knowledge involved in the educational tasks. This stage extensively contributes to the development of thinking skills which benefits in the acquisition of knowledge and the achievement of integration through obtaining, deepening, and refining new knowledge.

Steps to implement the lessons according to Marzano's dimensions of learning model: 
- Divide students to heterogeneous cooperative groups in terms of achievement and application of the required standards.

- Define and change the participant's roles every class as well as assert interaction among the participants.

- Instruct the students to follow the concepts involved in the concept map and to study the links between them to identify the elements and the relationships that connect them. The students can relate them to the prior information and deduce the information addressed in the present lesson.

- Instruct the students to connect new and prior learning meaningfully to enable them to comprehend it properly. Thus, knowledge gets meaningful.

- Discuss the outcomes with the students and emphasize the importance of re-validating them.

- Provide a summary of the main ideas in the lesson and connect the ideas.

- Provide some thought-provoking questions, carry out predictive investigations, and generate innovative ideas.

- Discuss the creative ideas with all groups, identify the innovative ones, and constantly motivate the participants to practice the different thinking skills in order to generate new ideas.

Final draft of the teacher's manual and the student's worksheets:

After preparing the manual and worksheets, they were reviewed by (10) reviewers in order to evaluate the appropriateness of the steps adopted in teaching to Marzano's dimensions of learning model, the strategies and methods derived from this model in teaching the course activities, the evaluation methods, and the activities involved in the worksheets to the course content. The author carried out the modifications they recommended to get the final draft.

B. Scale of creative thinking skills

The scale aims to evaluate creative thinking skills among the students of the Foundation Year. It consists of five questions that evaluate three skills (i.e. fluency, flexibility, and originality). The author prepared and applied it electronically.

Validity

- The validity of the reviewers: The scale's first draft was reviewed by (10) specialized professors in order to evaluate its accuracy and appropriateness to the objectives. They approved its validity after conducting a number of modifications.

- Internal validity: The scale was applied to a pilot study of (30) students not included in the sample to assert the internal validity of the items. Pearson correlation coefficient of the items and the total score of the scale were calculated. The correlation coefficients was in the closed interval [0.739-0.876]. Thus, they are statistically significant at the level of (0.01). Consequently, the items are valid.

Reliability

The scale's reliability was calculated using Cronbach's alpha $(\alpha)$. The reliability coefficient equaled ( 0.86$)$, indicating that the scale is highly reliable and valid for the field study.

\section{Results}

To answer the question of the study and to verify the validity of the hypothesis, T-Test was adopted to calculate the differences between score means of the two groups in the posttest of the creative thinking skills scale (i.e. fluency, flexibility, and originality).

Table 1 shows that the differences between score means of the control and experimental groups in the posttest of creative thinking skills' scale is significant at the level (0.000) in favor of the experimental group. This result verifies the hypothesis and indicates that the level of creative thinking skills (i.e. fluency, flexibility, and originality) among the members of the experimental group who studied using Marzano's dimensions of learning model is higher than that of the participants of the control group who were traditionally taught.

This result matches the findings of Alba'ali (2003), Al-Iraqi (2004), Hassanien ( 2006), Asfour (2007), Al-Hossan (2007), Alsalamat (2007), Habib (2008), Othman (2009), Fathalla (2009), Fathalla (2011), Kamel and Sayed (2011),Suliman (2010), Mohamed (2011), Al-Arian (2011), Al-Meselhi and Abdullah (2012),Abd Alkader (2012), Hanafi (2013), Al-Wassimi (2013), Mohamed (2014), Al-Qabas (2014), Saad (2014), Kazem and Mohamed (2014), 
Hussein (2015), and Radwan (2016). They reported the effectiveness of Marzano's dimensions of learning model in developing thinking among the students throughout the different educational stages.

Table 1. Significance of the Differences between Score Means of the Control and Experimental Groups in the Posttest of Creative Thinking Skills Scale

\begin{tabular}{|c|c|c|c|c|c|}
\hline Creative Thinking Skills & Group & $\begin{array}{c}\text { Arithmetic } \\
\text { Mean }\end{array}$ & $\begin{array}{c}\text { Standard } \\
\text { Deviation }\end{array}$ & $\mathrm{T}$ & T-Significance \\
\hline Fluency & Experimental & 9.680 & 2.428 & -9.665 & Significant at the \\
\hline & Control & 3.600 & 2.000 & & level of $(0.000)$ \\
\hline Flexibility & $\begin{array}{c}\text { Experimental } \\
\text { Control }\end{array}$ & $\begin{array}{c}12.720 \\
7.600\end{array}$ & $\begin{array}{l}2.372 \\
1.826\end{array}$ & -8.552 & $\begin{array}{l}\text { Significant at the } \\
\text { level of }(0.000)\end{array}$ \\
\hline Originality & $\begin{array}{l}\text { Experimental } \\
\text { Control }\end{array}$ & $\begin{array}{l}15.520 \\
10.480\end{array}$ & $\begin{array}{l}2.400 \\
1.851\end{array}$ & -8.314 & $\begin{array}{l}\text { Significant at the } \\
\text { level of }(0.000)\end{array}$ \\
\hline Total & $\begin{array}{c}\text { Experimental } \\
\text { Control }\end{array}$ & $\begin{array}{l}37.920 \\
21.680 \\
\end{array}$ & $\begin{array}{l}6.819 \\
5.437 \\
\end{array}$ & -9.311 & $\begin{array}{l}\text { Significant at the } \\
\text { level of }(0.000)\end{array}$ \\
\hline
\end{tabular}

\section{Discussion}

The students of the experimental group who studied the unit of interpersonal communication in the course of communication skills using Marzano's dimensions of learning model outperformed the students of the control group who were traditionally taught the selected unit because the model involved the following characteristics:

- The teaching strategies according to the model focused on the positive learner in terms of providing the students with the opportunity to compete, propose, correct, and discuss the solutions before showing them to the teacher. This helped them have creative thinking skills and achieve proper outcomes.

- Extend knowledge through various activities, such as comparing, classifying, inductive reasoning, deductive reasoning, analyzing errors, and creating evidence which enable the learner to reconstruct the information he/she learns and to understand the relationship among the different parts of knowledge (declarative and procedural) is the essence of the thinking process.

- Integrate thinking skills in all lessons through the educational assignments and activities was practiced in other similar situations.

- Explaining the lessons utilizing the model in the form of assignments and activities related to their lives and employing the strategies of problems solving and decision making to find answers helped students use their mental ability to think and find solutions to those problems.

- The methods, the teacher adopts in every lesson to form the productive habits of the mind (dimension 5), was represented by helping students verify the correct solution and review the steps of the solution and encouraging them to participate in discussing the proposed solutions to find the right solution.

- The model focuses on asking various questions that stimulate creative thinking through the educational tasks and activities that require practicing the different creative thinking skills in order to find the correct results of these activities, thereby developing the ability to use creative thinking skills

- Teaching the course using the model helped students think unconventionally and find different solutions to the problems they face.

\section{Recommendations}

The study makes the following recommendations:

- Redesigning the university courses according to Marzano's dimensions of learning model which enable students to understand the relationship among the parts of the course.

- Developing the university courses according to Marzano's dimensions of learning model.

- Training the students of the College of Education on using Marzano's dimensions of learning model in teaching and the methods of developing creative thinking skills in the course of teaching methods and in their practicum. 
- Training in-service teachers on using Marzano's dimensions of learning model in teaching and methods of developing creative thinking skills.

- Holding seminars, training courses and workshops for the supervisors and teachers to identify Marzano's dimensions of learning model, its advantages, and how to use it in teaching different courses.

- Evaluating the university courses according to Marzano's dimensions of learning model.

- Developing creative thinking skills among the student teachers at the Colleges of Education positively affects them later.

- Motivating the faculty members to employ the strategies of developing thinking in teaching.

- Providing the facilities, learning resources, and educational techniques required by teaching according to Marzano's dimensions of learning model.

\section{Conclusion}

Developing students' thinking is based on different curricula or independent teaching programs. Teaching models and strategies have emerged based on the application of basics and fundamentals derived from the results of the comprehensive researches. So educational institutions should develop their methods, teach their students thinking, and motivate them to free their intellectual and creative capacity. Marzano's dimensions of learning model is considered as an instructional classroom framework that involves five procedural steps focusing on the interaction between five dimensions of learning and the students' experience: Positive attitudes and perceptions about learning, acquisition and integration of knowledge, extension and refinement of knowledge, meaningful use of knowledge, and productive habits of mind. The educators use this model to design and plan the educational units, including the experiences they have to create an active and fruitful learning environment in which both the teacher and student can achieve the desired goals of the educational process. The author reports that for creative thinking, students are trained to develop mental habits through encouraging them to plan, use resources, evaluate their performance, be accurate and clear, create and engage in tasks even when answers or solutions are not immediately apparent.

The study recommended redesigning the university courses to comply with Marzano's dimensions of learning model and motivating the faculty members to employ the strategies of developing thinking in teaching.

\section{References}

Abd Alhaleem, R. (2011). Effectiveness of an electronic blended learning program based on the dimensions of learning model in developing the achievement of science, skills of reading pictures and social skills among the preparatory stage students with learning difficulties (Ph.D. dissertation). Faculty of Education, Suez Canal University.

Abd Alkader, M. (2012). Impact of utilizing Marzano's dimensions of learning model on developing higher-order thinking skills among the basic education students. Journal of Arabic Studies in Education and Psychology, 3(42), 91-148.

Abd-Almoneim, M. (2001). Evaluation of the impact of a program in psychological education on the development of some personal skills essential for the success in teaching profession "an experimental study" (Ph.D. dissertation). Faculty of Women, Ain Shams University.

Abo-Galala, S. (2006). Science curricula and the development of creative thinking (1st ed.). Amman: Dar Al Shorouk.

Abu-Azra, K. (2010). Impact of employing the strategy of (express, plan, evaluate) in teaching mathematics on the development of creative thinking among the $7^{\text {th }}$ grade primary students in Gaza (MA. thesis). Faculty of Education, Islamic University of Gaza.

Abu Lahia, K. (2011). Impact of utilizing drama in the Arabic language curricula on the development of creative thinking skills among the $3^{\text {rd }}$ basic grade students in North Gaza (MA. thesis). Faculty of Education, Al-Azhar University, Gaza.

Abu Shakur, A. (2013). The role of curricula in the development of creative thinking and sponsoring the gifted. Paper presented at the $10^{\text {th }}$ Arab Scientific Conference for the Gifted and Talented "Standards and Indicators for Excellence: Educational Reform and Sponsoring the Gifted and Talented" (pp. 585-598). Jordan: Arab Council for Gifted \& Talented. 
Afnan, B. (2011). Effectiveness of using a teaching strategy based on some dimensions of learning in the attitude and mathematical communication among the basic stage students at the Arabic Schools for Special Education in Amman. Journal of the Islamic University for Humanities, 19(1), 399-426.

Al-Adgham, R. (2005). Impact of using the dimensions of learning in teaching grammar on achievement, attitude and improvement of linguistic performance among the first secondary grade students in the Sultanate of Oman. Journal of the Faculty of Education in Damietta, 1(47), 260-312.

Al-Ahmadi, M. (2008). Using brainstorming technique in developing creative thinking skills and its impact on writing composition among the high school students. Journal of the Arab Gulf Mission, 107(29), 59-93.

Al-Aklabi, M. (2008). Effectiveness of cooperative learning strategy in teaching Hadith and Islamic Culture in the achievement and critical thinking skills among the first grade of high school students (Ph.D. dissertation). Umm Al-Qura University, Mecca.

Al-Arian, M. (2011). A proposed program based on Marzano's dimensions of learning model for the development of scientific thinking skills of the ninth basic grade students in Gaza (MA. thesis). Islamic University, Gaza.

Al-Atoum, A., Al-Jarrah, A., \& Beshara, M. (2011). Development of thinking skills: Theoretical and practical models (3rd ed.). Amman: Dar Al Massira.

Al-Bakr, R. (2008). Development of thinking through the curriculum (3rd ed.). Riyadh: Al-Rushd Bookshop for Publishing.

Alba'ali, I. (2003). Effectiveness of Marzano's dimensions of learning model in teaching science on the achievement and development of some science processes of second preparatory grade students. Journal of Scientific Education, 6(4), 65-94.

Al Faleh, S. (2010). Effectiveness of a proposed program of developing the skills of teaching creative thinking and the attitude towards it among science teachers of the intermediate stage in Saudi Arabia. Journal of King Saud University, 22(2), 327-363.

Al-Gafri, A. (2011). Marzano's dimensions of learning model. Kingdom of Saudi Arabia: General Directorate of Education in Mecca, Ministry of Education. Retrieved from www.uobabylon.edu.iq/eprints/pubdoc_3_30994_713.docx

Al-Ghamdy, S. (2013). The role of art education in the development of creative thinking. Paper presented at the $10^{\text {th }}$ Arab Scientific Conference for the Gifted and Talented "Standards and Indicators for Excellence: Educational Reform and Sponsoring the Gifted and Talented" (pp. 211-232). Jordan: Arab Council for Gifted \& Talented.

Al-Gharaybeh, S. (2014). Thinking skills and learning methods (5th ed.). Riyadh: Dar Al-Zahraa for Publishing and Distribution.

Al-Hossan, A. (2007). Effectiveness of dimensions of learning model in the development of some thinking skills and conceptual understanding of sciences and perceptions of the classroom environment among the sixth primary grade pupils. Journal of Arabic Studies in Education \& Psychology, 1(2), 215-225.

Al-Iraqi, S. (2004). Effectiveness of scientific activities-based program in the development of thinking skills among kindergarteners (Ph.D. dissertation). Faculty of Education, Ain Shams University, Egypt.

Al-Makhzoumi, N., \& Al-Bataniah, Z. (2012). Effectiveness of utilizing Marzano's dimensions of learning model in the development of reading comprehension skills among the primary stage students at the General Directorate of Education in Taif. The International Interdisciplinary Journal of Education, 1(9), 587-605.

Al-Meselhi, N., \& Abdullah, I. (2012). Effectiveness of Marzano's dimensions of learning model in the development of mathematical thinking among the fourth primary grade pupils. Journal of Arabic Studies in Education and Psychology, 3(31), 169-213.

Al-Mohamadawi, E. (2011). Impact of using oral questions according to Smith's Taxonomy on acquiring geographical concepts among the fourth literary grade students and the development of their creative thinking (MA. thesis). College of Education for Humanities/ Ibn Rushd, University of Baghdad.

Al-Momani, F., Al-Khatabia, A., \& Al-Qodah, M. (2015). The impact of planning models based on Marzano's dimensions of learning model on the conceptual understanding of the scientific concepts among the eighth-grade basic students in Jordan. Dirasat: Educational Sciences, 42(1), 185-198. https://doi.org/10.12816/0017344 
Al-Najdi, A., Rashed, A., \& Abd Alhadi, M. (2005). Recent trends in teaching science in the light of standards, development of thinking and Constructivism Theory (1st ed.). Cairo: Dar Elfekr Elaraby.

Al-Qabas, T. (2014). Impact of utilizing Marzano's dimensions of learning model on mathematical thinking and attitude towards mathematics among the basic stage students in Tafilah governorate. The International Interdisciplinary Journal of Education, 3(12), 233-251.

Al-qadi, H. (2009). The impact of conceptual maps in the development of creative thinking skills of the seventh-grade students in the Arabic language. Journal of Human Sciences, 46(8), 1-25.

Alsalamat, M. (2007). The effect of using a strategy based on Marzano's dimensions of learning model among upper basic stage students on their achievement of physics concepts and development of critical thinking skills and their attitudes towards physics (Ph.D. dissertation). Amman Arab University, Jordan.

Al-Sefi, A., \& Abo Dyak, A. (2017). The impact of using mind and conceptual maps on the achievement and development of creative thinking in science among the sixth primary grade students in Palestine. Al-Najah University Humanities Journal, 31(6), 1011-1048.

Al-Taib, I., Adam, A., \& Abdul Rahim, A. (2007). Development of thinking skills (1st ed.). Riyadh: Al-Rushd Bookshop for Publishing.

Al-Wassimi, E. (2013). Effectiveness of utilizing Marzano's dimensions of learning model in science achievement, development of creative thinking skills and achievement motivation among the first preparatory grade pupils. Egyptian Journal of Science Education, 16(1), 1-55.

Asfour, E. (2007). Impact of utilizing the systemic approach in teaching some mathematical concepts on achievement, learning retention, and development of geometric thinking skills among the fifth primary grade pupils (MA. thesis). Faculty of Education, Sohag.

Baali, I. (2003). Effectiveness of utilizing Marzano's dimensions of learning model in teaching science in the achievement and development of some learning processes among the second preparatory grade pupils. Journal of Science Education, 6(4), 65-94.

Barker, M., \& Rudd, R. (2007). Relationships between critical and creative thinking. Journal of Southern Agricultural Education Research, 3(1), 173-188.

Beghetto, R. (2007). Does creativity have a place in classroom discussions? prospective teachers' response preferences. Journal of thinking skills and creativity, 2(1), 1-9. https://doi.org/10.1016/j.tsc.2006.09.002

Brahimi, R. (2017). Effectiveness of using SCAMPER in the development of creative thinking among the fourth primary grade students: A field study at Sadeqi Al-Sadegh School in Djelfa (MA. thesis). Faculty of Social Sciences and Humanities, University Ziane Achour - Djelfa.

Fathalla, M. (2009). Effectiveness of Marzano's dimensions of learning model in the development of the conceptual understanding of science and habits of mind among the sixth-grade primary pupils. Egyptian Journal of Science Education, 12(2), 83-125.

Fathalla, M. (2011). Effectiveness of Marzano's dimensions of learning model in the development of conceptual understanding of science and habits of mind among the sixth primary grade pupils in Unaizah, Saudi Arabia. The Educational Journal, 25(98), 145-199.

Francie, M., Tim, F., \& Tiffany, J. (2013). How can one specify and teach thinking skills? European Journal of Behavior Analysis, 14(2), 285- 293. https://doi.org/10.1080/15021149.2013.11434461

Guo-Qing, Z. (2014). Training of scientific thinking methods in teaching of inorganic and analytical chemistry. Journal of Chemical and Pharmaceutical Research, 6(7), 1503-1508.

Habib, E. (2008). Effectiveness of using the dimensions of learning model in achievement, decision-making, and attitude towards sciences among the first preparatory grade students (Ph.D. dissertation). Faculty of Education, Ain Shams University.

Habib, M. (2007). Recent trends in teaching thinking (independent strategies for the new millennium) (2nd ed.). Cairo: Dar Elfekr Elaraby.

Hanafi, K. (2013). Effectiveness of a program based on Marzano's dimensions of learning model in teaching mathematics and its impact on the development of conceptual understanding and creative thinking skills among the first secondary grade students (Ph.D. dissertation). Faculty of Education, Fayoum University. 
Hassanien, M. (2006). Effectiveness of a program based on the dimensions of learning model in teaching physics in the acquisition of concepts, complex thinking and attitude towards learning among the first secondary grade students (Ph.D. dissertation). Faculty of Education, Minia University.

Hussein, O. (2015). Effectiveness of utilizing Marzano's dimensions of learning model in teaching science in the acquisition of scientific concepts, development of critical thinking, and achievement motivation among the preparatory stage students (MA. thesis). Faculty of Education, Minia University.

Ibrahim, A. (2006). The impact of multiple intelligences program of science teachers on developing creative teaching and problem-solving skills among students. Journal of Scientific Education-Al-Azhar University, Gaza, 9(4), 27-89.

Jarwan, F. (2010). Teaching thinking: Concepts and practices (5th ed.). Amman: Dar Al Fikr for Publishing and Distribution.

Kamel, M., \& Sayed, Y. (2010). The impact of utilizing the dimensions of learning model on the development of reading map skill and critical thinking among the fifth primary grade pupils with learning difficulties. Journal of the Faculty of Education-Assiut University, 26(1), 326-372.

Kamel, M. (2011). The impact of utilizing the dimensions of thinking model in teaching social studies on the development of geographical skills and creative thinking among the intermediate stage students in Saudi Arabia. Educational Journal, 30, 326-374.

Karwowski, M., Gralewski, J., Lebuda, I., \& Wisniewska, E. (2010). Creative teaching of creativity teacher's Polish perspective. Journal of Thinking Skills and Creativity, 2(1), 57-61. https://doi.org/10.1016/j.tsc.2006.10.004

Kazem, S., \& Mohamed, H. (2014). Impact of utilizing Marzano's dimensions of learning model on the development of probe thinking in geography among the second intermediate grade students. Journal of College of Basic Education College for Educational and Human Sciences-University of Babylon, 18, 523-542.

Marzano, R., Pickering, D., Arredondo, D., Blackburn, G., Brandt, R., \& Moffett, C. (1998). Dimensions of learning: Teacher's manual (trans. Jaber Abdel-Hamid, Safaa Alasar and Nadia Sharif). Cairo: Dar Quba' for Printing, Publishing and Distribution.

Marzano, R., Pickering, D., Arredondo, D., Blackburn, G., Brandt, R., \& Moffett, C. (1999). Dimensions of learning: Different design of the classroom (trans. Jaber Abdel-Hamid, Safaa Alasar and Nadia Sharif). Cairo: Dar Quba' for Printing, Publishing and Distribution.

Marzano, R., Pickering, D., Arredondo, D., Blackburn, G., Brandt, R., \& Moffett, C. (2000a). Dimensions of learning: Performance assessment (trans. Jaber Abdel-Hamid, Safaa Alasar and Nadia Sharif). Cairo: Dar Quba' for Printing, Publishing and Distribution.

Marzano, R., McTighe, J., \& Pickering, D. (2000b). Dimensions of learning: Assessing student outcomes: Performance assessment using the dimensions of learning model (trans. Jaber Abdel-Hamid, Safaa Alasar and Nadia Sharif). Cairo: D Dar Quba' for Printing, Publishing and Distribution.

Marzano, R., \& Kendall, J. (2007). The new taxonomy of educational objectives (2nd ed.). Thousand Oaks, CA: Corwin Press.

Mikhael, N. (2009). Employing Marzano's dimension of learning/thinking model in teaching mathematics:" Future perspective". Paper presented at the curricula seminar: Future perspectives.

Mohamad, A. (2014). Effectiveness of a proposed program in mathematics based on the dimensions of learning model in the achievement, mathematical thinking and achievement motivation among the primary stage low-achievers (Ph.D. dissertation). Faculty of Education, Minia University.

Mohamed, H. (2011). Effectiveness of a learning dimensions-based program in the development of some thinking skills among the first three primary grade's pupils (MA. thesis). Faculty of Education, Ain Shams University.

Mohamed, I. (2003). Effectiveness of using Marzano's dimensions of learning model in teaching science in achievement and development of some learning processes among the second preparatory grade pupils. Journal of Science Education, 6(4), 65-94.

Othman, R. (2009). The impact of a proposed strategy based on metacognition strategies and Marzano's model using multimedia in teaching mathematics on the development of metacognition skills and achievement among high school students (Ph.D. dissertation). Faculty of Education, Beni Suef University. 
Prodfit, A. (2010). The examination of problem-solving processes by fifth grade children and effect on problem solving performance. Journal of Family Psychology, 41(3), 3932-3941.

Qattami, Y. (2007a). Thirty habits of mind to teach thinking. Amman: Dinomu for Publishing and Distribution.

Qattami, Y. (2007b). Teaching children thinking (1st ed.). Amman: Dar Al Massira for Publishing and Distribution.

Radwan, Y. (2016). Effectiveness of a program based on Marzano's dimensions of learning model in the development of productive thinking skills in mathematics among the ninth basic grade students (MA. thesis). Faculty of Education, Islamic University, Gaza.

Saad, H. (2014). The impact of utilizing Marzano's dimensions of learning model on the development of probe thinking in geography among the second intermediate grade students (MA. thesis). College of Education for Humanities, University of Babylon, Iraq.

Salih, M., \& Bashir, H. (2005). Using the dimensions of learning model in developing the skills and concepts associated with some educational experiences of the kindergartener. Journal of Studies in Curriculum and Instruction, 10(107), 183-233.

Sandro, S. (2017). The effect of English language learning on creative thinking skills: A mixed methods case study. Canadian Center of Science and Education, 10(3), 82-94. https://doi.org/10.5539/elt.v10n3p82

Shamri, Z. (2012). The effectiveness of conceptual maps strategy in the formation of the technical picture written and the development of creative thinking in the material expression skills of students third grade average in the Kingdom of Saudi Arabia. The Islamic University of Educational and Psychological Studies Journal, 2(20), 275-329.

Soliman, M. (2004). The impact of training on the dimensions of learning model in teaching performance for teacher students in Division of the Arabic Language. Journal for Reading and Literacy, 38, 47-83.

Sorour, A. (2013). Effectiveness of a proposed strategy in developing the ability to formulate mathematical problems and attitude towards problem solving among basic education students in the light of the international studies TIMSS \& PISA. Paper presented at the $10^{\text {th }}$ Scientific Conference of the Egyptian Association for Mathematics "Recent Trends in the Development of Mathematics Instruction" (pp. 1-32). Egypt: Dar Al Diafa, Ain Shams University.

Sriwongchai, A., Jantharajit, N., \& Chookhampaeng, S. (2015). Developing the mathematics learning management model for improving creative thinking in Thailand. Canadian Center of Science and Education, 8(11), 77-87. https://doi.org/10.5539/ies.v8n11p77

Suliman, F. (2010). The effectiveness of Marzano's dimensions of learning model in developing the skills of solving the mathematical problems among the ninth basic grade students (MA. thesis). College of Education, Sultan Qaboos University, the Sultanate of Oman.

Waters, T., \& Marzano, R. (2006). School district leadership that works: The effect of superintendent leadership on student achievement, a working paper from. Mid-Continent Research for Education and Learning, 1-25.

Widiana, I., \& Jampel, I. (2016). Improving students' creative thinking and achievement through the implementation of multiple intelligence. Journal of Evaluation and Research in Education, 5, 246-254. https://doi.org/10.11591/ijere.v5i3.4546

Yee, M., Widad, B., Jailani, B., Tee, T., Razali, B., \& Mimi, M. (2011). The level of Marzano higher order thinking skills among technical education students. International Journal of Social Science and Humanity, 1(2), 121-125. https://doi.org/10.7763/IJSSH.2011.V1.20 